\title{
Thermo-Mechanical Degradation for Hard Barium Ferrite- Natural Rubber Composites
}

\author{
Mahmoud Hosseny Makled \\ Physics Department, Faculty of Science, Benha University, Benha 13518, Egypt
}

\begin{abstract}
$\mathbf{T}$ HE aim of this work is to evaluate the thermal stability of the natural rubber- hard barium ferrite composites at different contents of ferrite particles. The tensile, hardness and swelling were tested before and after ageing for 15,30 and 45 days at $80{ }^{\circ} \mathrm{C}$. The composites were prepared by two roll mixing method. In this study the composites vulcanizes were cured up to respective cure time of each sample. Then aged for different periods for mechanical characterization. SEM images indicate no aggregation of the ferrite particles before and after mixing with rubber. Thermal stability of the composites during the first 2 weeks is noticed. After 15 days of aging, all the mechanical parameters decreased drastically with increasing aging time up to 30 days. The FTIR reflects the thermal stability of the composites. A Swelling test showed the higher thermal stability and the optimum vulcanization parameter of the composites.For all samples, the thermal degradation increased after 15 days
\end{abstract}

Keywords: Thermal degradation, Hard ferrite, Natural rubber, Mechanical properties

\section{Introduction}

For producing highly effective magnetic polymer we should raise the level of magnetic properties in addition to improving their work ability [1]. The mechanical properties of polymer bonded magnets are strongly influenced by the size, shape, type, loading, and dispersion of the magnetic filler, as well as the matrix properties and the interfacial adhesion between the filler and the polymer matrix [2-4].

Natural rubber degradation can be caused by many factors, such as elevated temperature, irradiation, humidity, impurities, mechanical load, and chemicals [5-7].

A number of general classes of chemical mechanisms are very important in thermal decomposition of polymer such as, a) random chain scission, in which chain scissionscission occurs at apparently random location in the polymer chain, b) end-chain scission, in which individual monomer units are successively removed at the chain end [8-10]. Tensile testing is the main test which can be used for assessing the effect of different degrading agents on the polymer or polymer-composites. This is because of the simplicity of the test with a uni-axially applied load and the determination of several useful parameters such as tensile strength, elongation, and modulus [11].
In our previous works, most of the physical properties of natural rubber- $\mathrm{BaFe}_{12} \mathrm{O}_{19}$ composites were characterized in details at different ferrite loading (preparation, magnetically, mechanically, dynamically, electrically and thermal stability) [12-15]. Our results reflect good adhesion between the ferrite particles and NR matrix, even at high ferrite loading. These singular properties of the composites encouraged us to study the consistency of the composite under some external destructive aging, such as heat resistance and radiation.

The present manuscript is an attempt to understand the thermal stability of the NR$\mathrm{BaFe}_{12} \mathrm{O}_{19}$ composites for long aging time.

\section{Experimental}

Hexagonal barium ferrite $\mathrm{BaFe}_{12} \mathrm{O}_{19}(\mathrm{BaF})$ phase was prepared by the co-precipitated method according to Makled et al. [12]. Powder having a coercive force $5 \mathrm{kOe}$ and $65 \mathrm{emu} / \mathrm{g}$ saturation magnetization with $45-200 \mu \mathrm{m}$ particles size was selected to mix with smoked rubber sheet at various $\mathrm{BaF}$ loading up to $120 \mathrm{phr}$ (part per hundred rubber) to form rubber ferrite composites (RFC). The recipe and mixing procedures were reported in a previous work [13].

Scanning electron micrographs (SEM) for RFC were obtained from a fractured and polished

mhmakled@fsc.bu.edu.eg 
surface under liquid nitrogen. The polished fractured surface was coated with carbon prior to the SEM investigation. The IR analysis was per-formed using a PYE spectrophotometer over the range $500-4000 \mathrm{~cm}^{-1}$.

Swelling test

Swelling of the NR-Ferrite vulcanized composites was carried out on a test piece weighing about $2 \mathrm{~g}$ cut from the compression molded RFC samples. The samples were immersed in pure toluene at room temperature for two days to allow the swelling to reach diffusion equilibrium. Then, the test pieces were taken out and the adhered liquid was rapidly removed by blotting with filter paper $[16,17]$. The swelling ratio was estimated according to the equation

$m_{R}=\frac{m_{t}-m_{0}}{m_{0}}$

where, $m_{0}$ is the weight of test piece before swelling and $m_{t}$ is the weight of the swelling test piece after time $t$ of immersion.

The specimens for mechanical measurements were prepared by molding the RFC into the thin sheets with $2 \mathrm{~mm}$ thickness at $150^{\circ} \mathrm{C}$ under 140 $\mathrm{kg} / \mathrm{cm}^{2}$ hydraulic pressures. The vulcanization was carried out up to the respective cure times of the samples. The cure time of maximum torque $t_{90}$ was obtained from dynamic tester model ( DMS 200 SII Seiko)

To measure the thermal ageing, the used samples were heated for 15,30 and 45 days at 80 ${ }^{\circ} \mathrm{C}$ according to ASTM 572. The aged specimens were left at room temperature for at least $10 \mathrm{hr}$ before the mechanical properties are tested.

The tensile stress was measured according to ASTM D-412, using Shimadzu Tensile System (AG-1000D)..The Hardness (shore) of the molded samples were tested using Durometer Hardness (Asker type a) according to ASTM D-2240.

\section{Results and Discussion}

Figure 1 ( $a$ and $b$ ) show the ferrite particles morphology and its distribution in rubber matrix at $120 \mathrm{phr}$. It is clear that the particles are disaggregated and have sharp edges and irregular shapes, which may assist good adhesion between these types of particles and rubber matrix. In Figure $1 \mathrm{~b}$, the homogeneous and the broad particle distribution can be noticed also, there is no tendency of agglomeration formation or percolation at the present RFC,even at high ferrite loading.
Figure $2 \mathrm{a}$ and $\mathrm{b}$, describes the effect of aging time on both of tensile strain and stress. Slightly variation in mechanical parameters is observed in the first two weeks, followed by a remarkable. After 30 days the composites reached the asymptotic values. On the other hand, the decrease in stress and strain was more drastically at low ferrite content,while at high ferrite loading about $60 \mathrm{Phr}$, the dependence of both strain and stress on the ferrite loading becomes insensitive by increasing ferrite content in a rubber matrix. On the other hand, no increase in the mechanical behavior with aging time was noticed, which reflects the optimum vulcanization of the composites. Normally, by heating rubber compounds, two competing reactions generate, namely the crosslink formation and chain scission. In the present composites only the chain scission is initiated at about 15 days. The degree of chain scission is manly depends on the amount of vulcanized rubber in the composites. This is decreased by increasing filler content in the rubber matrix. So the high decrease in the mechanical properties was recorded at low ferrite content.

Tensile modulus $\mathrm{Y}$ was also estimated from the stress-strain curves for the present samples and illustrated in Fig. 3 versus aging time. In general Y increases with increasing filler content due to the increasing composite hardness, due to the addition of hard fillers. But by curing the composites tensile models reflects similar behaviors as tensile test. It decreases drastically after 15 days of aging time and the decreasing slow down after 30 days.

Hardiness (shore) is considered as one of the important factors in polymer degradation [18] Because it reflects the degree of the crosslinking of polymer composites .Hardness was measured for the samples under investigation and illustrated in Fig. 4 with different aging time. Shore hardness was found to decrease with increasing aging time recording about $25 \%$ decrease in the composites hardness at 45 aging days.

From the previous discussion, one can notice that all the measured mechanical parameters reflect high thermal stability of the present composites up to 15 days of aging at $80^{\circ} \mathrm{C}$.

An attempt was done to clarify the change in the mechanical characteristics, stress-strain, tensile modulus, and shore hardness with increasing aging time for the present composites, using FTIR investigation and swelling test . 


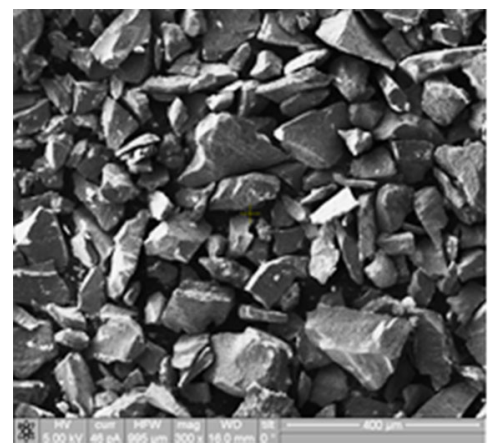

Fig. 1a. SEM image for barium ferrite

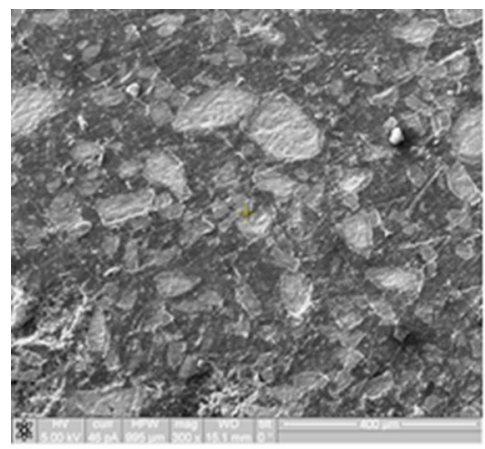

Fig. 1b. SEM image for RFC at $120 \mathrm{phr}$

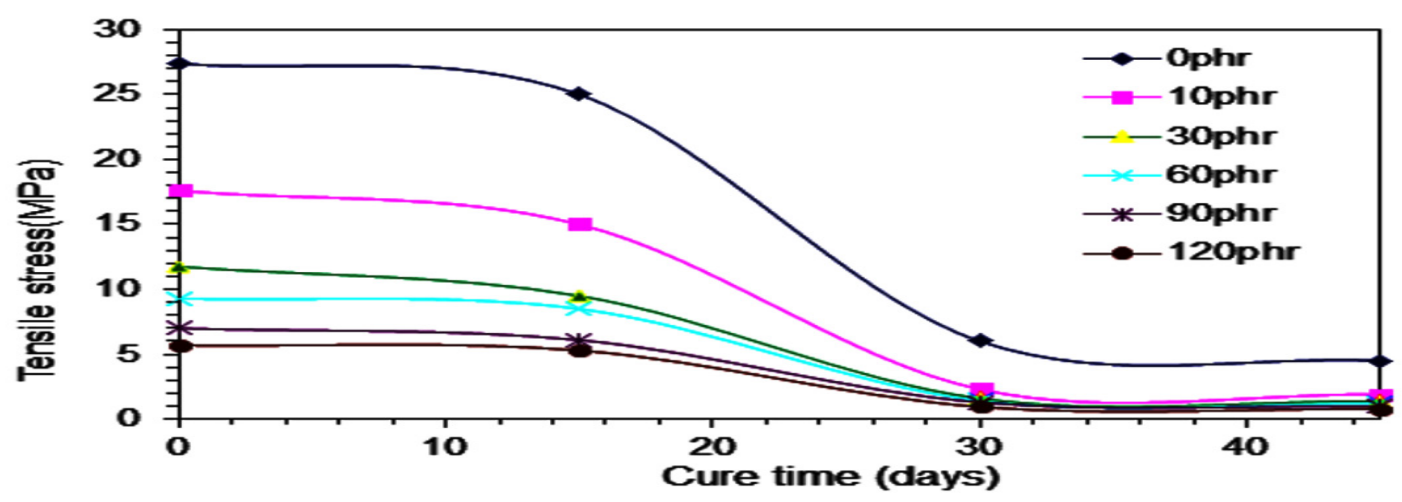

Fig. 2a. Effect of Cure time on the Tensile stress of RFC.

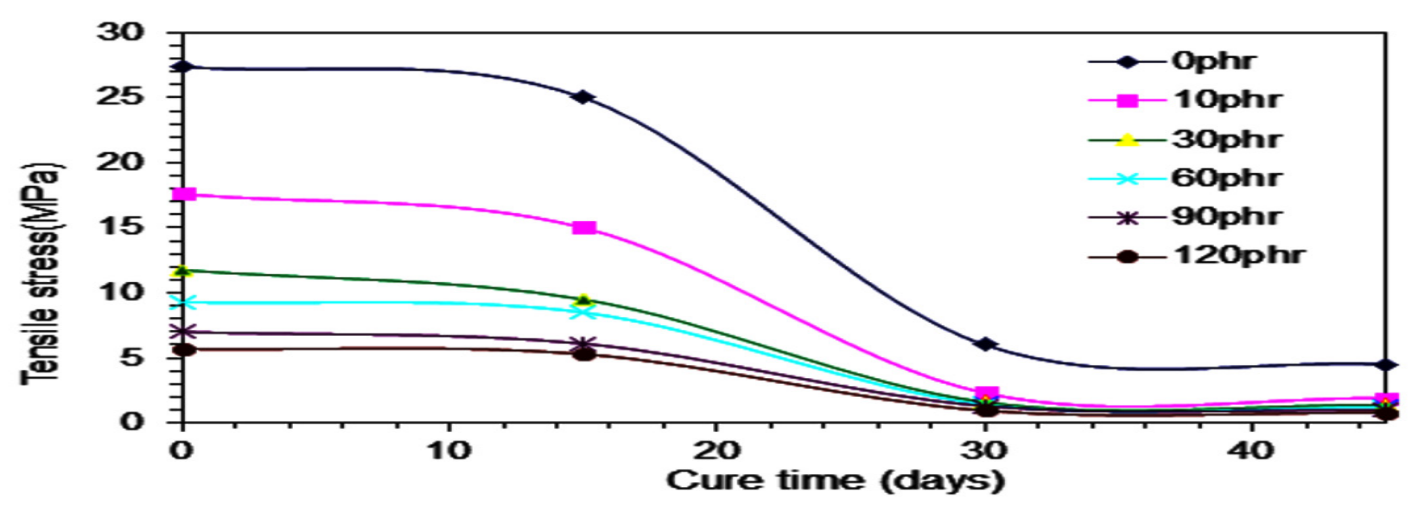

Fig. 2b. Effect of Cure time on the Tensile strain of RFC.

Egypt. J. Phys. 47, No. 1 (2019) 


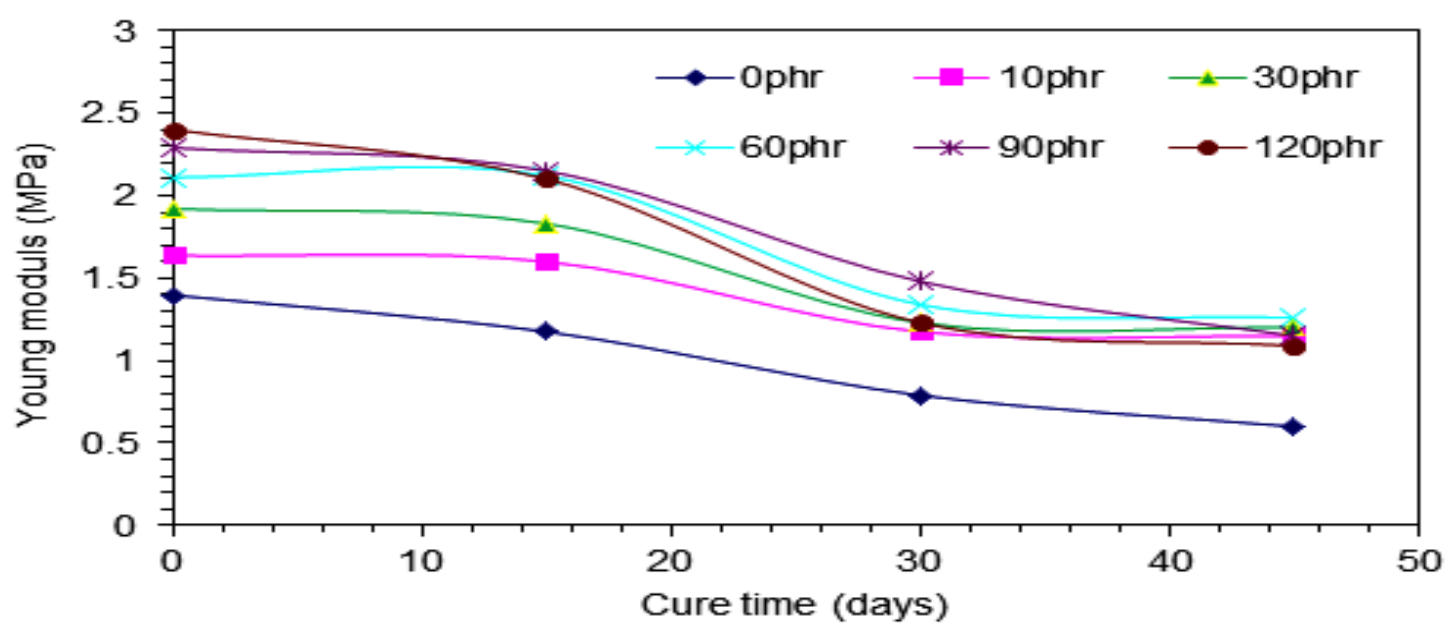

Fig. 3. Effect of Cure time on the tensile modules of RFC.

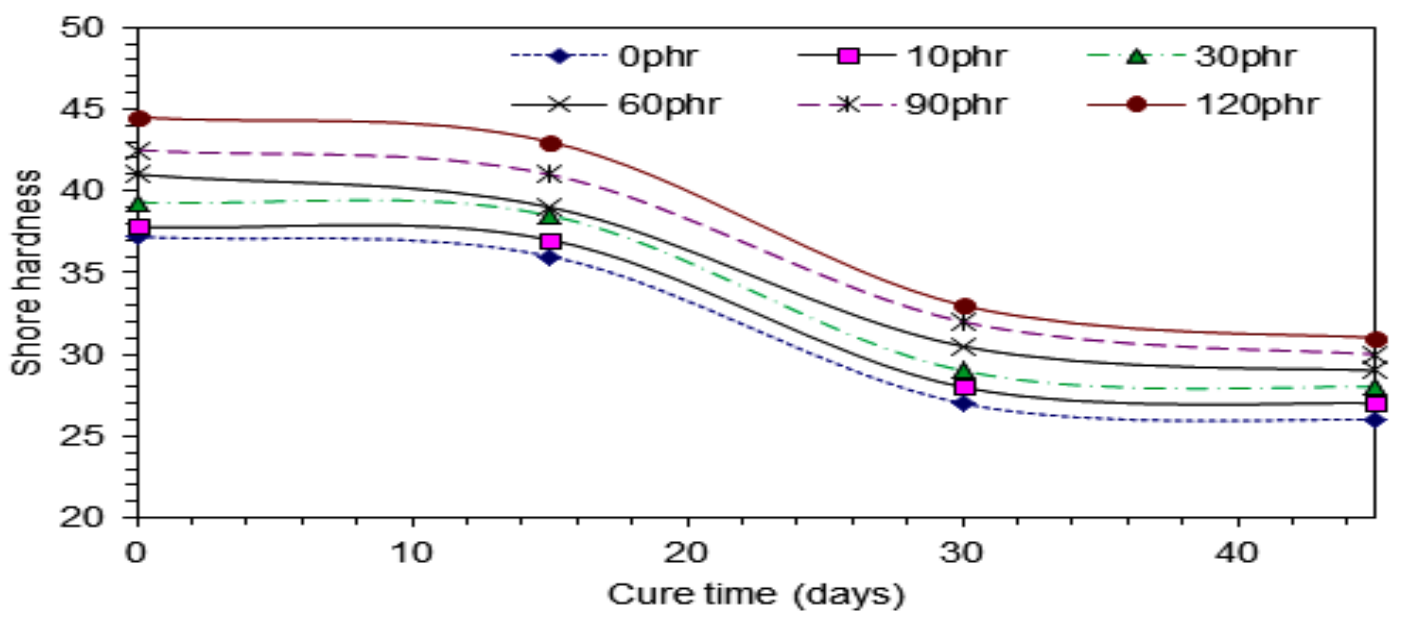

Fig. 4. Effect of Cure time on the Shore hardness of RFC.

Figure 5 shows the FTIR spectrum for the sample with $90 \mathrm{phr}$ as an example at different curing time. From this figure, one can notice a none-significant change in the position of the beaks recorded which reflects the thermal stability of the composites.

The samples swelled due to the penetration of toluene solvent in the vulcanized rubber matrix. The losses percentage in composite weight corresponding to the extracted linear portion of the rubber composite, and or the degraded chains at different aging times for the present samples are illustrated in Fig. 6. The results demonstrated that, thermal degradation occurred in rubber matrix due to the aging of RFC composites up to 15 days, which appears as a dissolved of rubber matrix in the solvent leading to losses in composite weight. The weight losses increase after 15 days reaching asymptotic values beyond 30 days aging at $80^{\circ} \mathrm{C}$.

The stability of the mechanical properties for the present RFC after 30 aging days as seen in all figures is an evidence for the stability, homogeneity and the optimum preparation condition of the composites. Only small amount of the rubber chains were scission in a long period of aging time. 


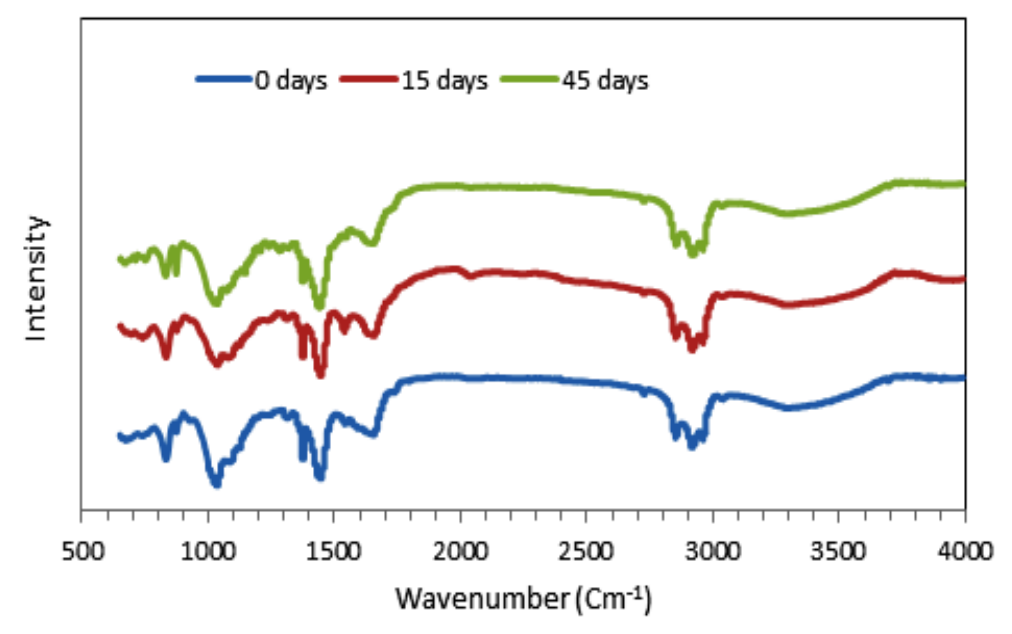

Fig. 5. Ft-IR for BFC at $90 \mathrm{phr}$.

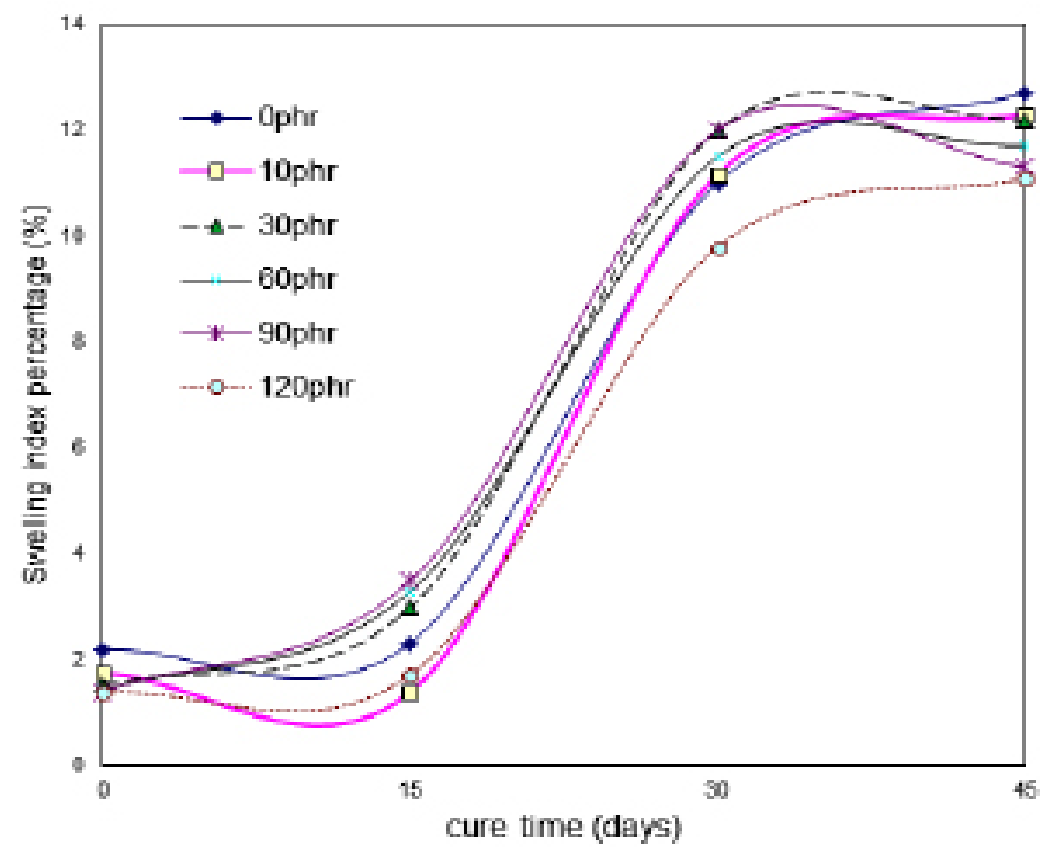

Fig. 6. Swelling index percentages of RFC.

\section{Conclusion}

All the obtained results reflected a high thermal stability of the present $\mathrm{BaFe}_{12} \mathrm{O}_{19}-\mathrm{NR}$ composites. The composite tensile strength, strain at break and Young moduli were influenced by the aging time and the volume fraction of ferrite. The swelling test indicates the homogeneity and the optimum preparation condition of the composites. The degradation increased after 15 days, whereas a stability of the mechanical properties started beyond 30 days of aging.

\section{References}

1. Philippova,O., Barabanovan, A., Molchanovn, V. and Khokhlov, A., Europ.Polym. J. 47, 542 (2011).

2. Soloman, M.A., Kurian, P. and Anantharaman, M.R., Progress in Rubber, Plastics and Recycling Techno.18, 269 (2002).

3. Datta, J., Kosiorek, P. and $\mathrm{W}^{3} \mathrm{och}, \mathrm{M}$., Iran Polym. J. 25, 1021 (2016).

4. Mente, P., Motaung, T.E. and Hlangothi, SP., Polym. Sci. 2,1 (2016).

Egypt. J. Phys. 47, No. 1 (2019) 
5. Yahya,Y. S., Azura, A. R. and Ahmad, Z., J. Phy. Sci.22, 1 (2011).

6. He,C.,Wang,Y.,Luo,Y.,Kong,L.and Peng, Z.,J. Polym. Eng. 33, 331 (2013).

7. Fainleib, A., Pires, R. V., Lucas, E. F. and Soares,B. G., Polímeros, 23, 441 (2013)

8. Visakh,P. M. and Arao,Y., Thermal Degradation of Polymer Blends, Composites and Nanocomposites, $1^{\text {st }}$, springer (2012).

9. Brnardic, I., Acan, J.I., Vankovic, H. and Ivankovic, M., J. Appl. Polym. Sci.107, 1932 (2008).

10. Obasi, H. C., Ogbobe, O. and IgweI. O., Inter. J.Polym. Sci. ID.140682, 1 (2009)

11. Mathew, S.,Varghese, S. and Joseph, R. Prog. Rub. Plast. Recycling Technol. 29, 1 (2013).

12. Makled, M.H., Matsui,T., Tsuda, H., Mabuchi, H., El-Mansy, M.K. and Morii, K., J. Ceram. Soci. Japan ,112, 2000 (2007).
13. Makled, M.H., Matsui, T., Tsuda, H., Mabuchi, H., El-Mansy, M.K. and MoriiK. J. Mater. Process. Technol. 160, 229 (2005).

14. Khaled, H. M. and Makled, M. H., Advan. Chem. Eng. Sci. 2, 350 (2012).

15. Makled, M. H., J. Appl. Polym. Sci. 126, 967 (2012).

16. Durmaz, S.,Fank, S. and Okay, O., Macromolecular Chem. phy. 203, 663(2002).

17. Wahit, M. U., Hassan, A., Ibrahim, A. N., Zawawi, N.A. and, Kunasegeran, K., Sains Malaysiana, 44, 1615 (2015).

18. Sridharan, K. and Elangovan, K., J. Chem. Pharmaceutical Res. 8, 553 (2016).

(Received: 9/ 8 /2018; accepted:24/10/2018)

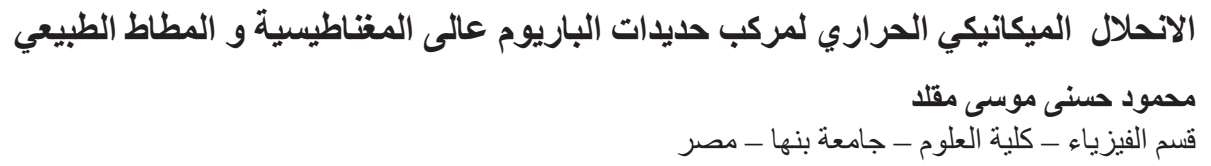

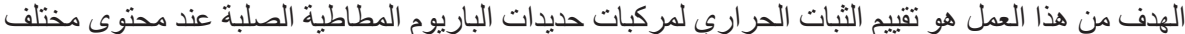

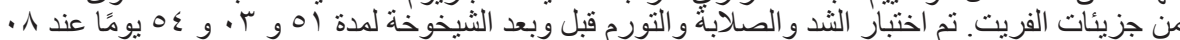

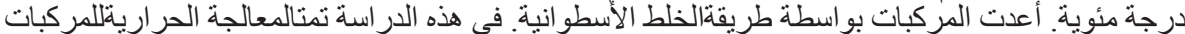

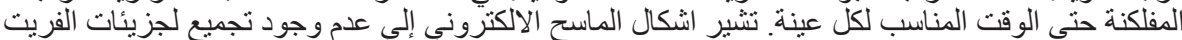

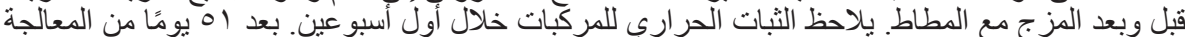

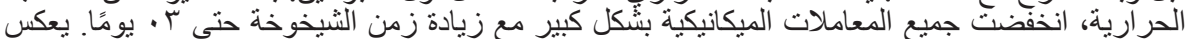

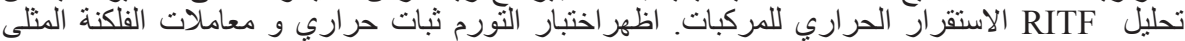

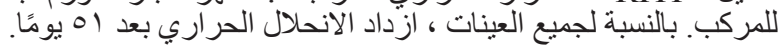

